\title{
Thermogravimetry as a Research Method in the Transformation Processes of Waste Rubber and Plastic Products for Energy Carriers (WtE and WtL Processes)
}

\author{
Ewa Rostek ${ }^{1}$, Krzysztof Biernat ${ }^{2}$ \\ ${ }^{1}$ Centre of Materials Testing and Mechatronics, Motor Transport Institute, Warsaw, Poland \\ e-mail: ewa.rostek@its.waw.pl
}

${ }^{2}$ Department of Fuels and Renewable Energy, Automotive Industry Institute, Warsaw, Poland

Cite as: Rostek, E., Biernat, K., Thermogravimetry as a Research Method in the Transformation Processes of Waste Rubber and Plastic Products for Energy Carriers (WtE and WtL Processes), J. sustain. dev. energy water environ. syst., 1(2), pp 163-171, 2013, DOI: http://dx.doi.org/10.13044/j.sdewes.2013.01.0012

\begin{abstract}
The paper describes the basic problems regarding the possibility of using waste plastics and tire rubber waste as raw materials for the preparation of liquid energy carriers for transport (WtL processes) or directly to energy use in a WtE. Simultaneous measurements were performed at Thermal Analyzer STA 449 F3 Jupiter's (Netzsch). The study was conducted for waste samples of different density polyethylene, polyethylene terephthalate and rubber from waste tires. Gasification process of subjecting the sample was recorded TG and DSC curve, observing changes in mass, temperature and enthalpy. These studies were carried out in order to pre-determine the kinetics of thermal decomposition. The study, conducted in an atmosphere of argon/nitrogen (non-oxidizing atmosphere), both in terms of the changes of enthalpy and mass are summarized in the respective charts.
\end{abstract}

\section{KEYWORDS}

Waste to Energy, Waste to Liquid, Plastic Waste, TG/DSC, Kinetics of Thermal Decomposition

\section{INTRODUCTION}

The growing amount of plastic and tyre rubber waste is generating more and more environmental problems worldwide. The present rate of economic growth is unimaginable without saving of fossil energy like crude oil, natural gas or coal. Suitable waste management is another important aspect of sustainable development. Plastic and rubber wastes represent a considerable part of municipal wastes, furthermore huge amounts of waste arise as a by-product or faulty product in industry and agriculture [1-3].

Traditionally the destruction of wastes via incineration and landfill deposition was regarded as the preferred treatment options. However the worlds reliance on the ever decreasing resources of fossil fuel energy and global awareness in the rise of pollutant emissions particularly carbon dioxide $\left(\mathrm{CO}_{2}\right)$ has led to more stringent environmental legislation.

Nowadays there are three ways to utilize plastic and tyre rubber waste: landfilling, incineration with or without energy recovery and recycling. The largest amount of wastes is disposed of by landfilling (40\%), recycling is about 39\%, and incineration with energy recovery is only $20 \%$. Energy recovery from waste substances is referred to today as the processes WtE (Waste to Energy) [4-6].

It was found that the degradation is a suitable technique for converting waste polymers into liquid hydrocarbons. The volatile products could be used as feedstock components, e.g. in refineries. Their further utilization for petrochemical purposes has 
not yet been solved. One possibility is a fuel-like application or mixing in fuels as a blending component. Before blending the high olefin content is to be saturated with hydrogen, or hydro isomerized.

These steps result in a high quality synthetic diesel fuel, with high cetane number, and theoretically free from sulphur, nitrogen and metals. In practice these fractions generally have a very low heteroatom content, even if the raw material was pure and not waste, because most polymers contain dopes, e.g. sulphur containing anti-flame or antioxidant additives, etc.

\section{DERIVATOGRAPHY AS AN ANALYTICAL METHOD}

The processes of plastic and rubber waste into fluid (liquid or gaseous) components of the engine fuels or into energy carriers require a supply of energy in the form of heat in order to break the existent chemical bonds and create new ones. Therefore, in order to define the optimum conditions for the transformation process it would be essential to define the kinetics of those processes. Due to the complex and varied chemical structures which form wastes of plastic or rubber, it is not fully possible to define the kinetics at each transformation stage.

The choice of parameters of those wastes transformation processes is very important, and the values of the parameters result, for the time being, from technological practice and have not yet been determined unequivocally. It should be remembered that the process of plastic and rubber waste transformation into energy components (liquid and gaseous hydrocarbons, in WtL and WtE processes) is not a natural process, and it leads to an accelerated growth of entropy of the environment despite the conventionally accepted for waste substances, zero values of carbon dioxide emissions in LCA (Life Cycle Assessment).

New sources of energy should be looked for, such as all types of waste materials, which are also by-products of consumption processes (WtL processes). Taking into consideration the optimisation of the processes leading to the obtaining of energy carriers, it is now less significant to categorise raw materials according to their origin. It is much more important to use them as effectively as possible with the lowest possible values of energy put into the transformation processes. Consequently, the production of liquid energy carriers, i.e. fuels, should be treated as the XtL type of process, in which the materials transformed into liquid fuels can be any present or future waste materials, ensuring at the same time low-emissions transformation technologies and the value of the EROEI ("Energy Returned On Energy Invested") index substantially higher than one.

The selection of the optimum parameters of the $\mathrm{WtL}$ or the $\mathrm{WtE}$ processes, calls for the recognition of the kinetics of transformation processes together with the determination of the intermediate products and their life during the process. It is also essential to determine the changes in enthalpy in the transformation process in the function of the variable state of matter, which could allow a development of the optimum conditions for liquefaction of the raw material. Due to the varied composition of raw materials in the $\mathrm{WtL} / \mathrm{WtE}$ processes, an unequivocal determination of the optimum parameters of the transformation processes is rather complex and will require statistical processing [7-9].

For these reasons, the TGA (Thermogravimetric Analysis) method combined with DSC (Differential Scanning Calorimetry) was selected for preliminary exploratory research. The thermogravimetric analysis (TG), combined with differential scanning calorimetry (DSC), allows to accurate course identification of thermal changes that proceed in examined specimen. It is also possible to identify the decomposition products in on-line mode. The evaluation of kinetics of the thermal decomposition process for 
different atmospheres, with or without participation of catalyst, is feasible as well. Therefore this methods provide not only the determination of technological parameters of thermal decomposition or the pyrolysis, but may also be useful to estimate the effectiveness of gasification process. The significant feature of thermogravimetric processes is the possibility of precise definition of the enthalpy value and its sign for the exactly defined temperature range. According to the International Confederation for Thermal Analysis and Calorimetry (ICTAC), thermal analysis (TA) means the analysis of the change in a sample which is related to an imposed temperature regime [10]. Calorimetry means the measurement of heat e.g. heat of the reaction or heat of the phase state change (vaporization, etc.). The kind of the property whose change is tested and analysed is assumed to be the basic classification criterion of thermoanalytical techniques.

Thermogravimetric analysis (TGA) is a well-established method in the determination of the weight loss characteristics and its associated reaction kinetics [11-14]. Pyrolysis thermogravimetric analysis involves the thermal degradation of the sample (typically 5-20 mg sample weight) in an inert atmosphere with simultaneous recording of the loss in weight of the sample as the temperature is raised at a uniform rate. The analysis provides net weight loss, and calculation of kinetic parameters is based on simplifying assumptions which do not necessarily correspond to the complex chemical reactions in the thermal degradation of the waste sample.

Thermogravimetry is a technique used to define the change in the mass of a sample caused by a temperature regime imposed on the sample, or a technique used to measure the mass of the sample in the function of temperature. The ICTAC guidelines advise the use of the abbreviation TGA (Thermogravimetric Analysis). A thermogravimetric measurement results in a thermogravimetric curve (TG curve) - the dependence of the sample mass on time/temperature.

Differential scanning calorimetry (DSC) means a technique in which the change of the difference in the heat flow rate to the sample and to the reference sample is analysed while they are subjected to a temperature regime, or a technique where the change of the difference in the heat flow rate to the sample and to the reference material is measured as a function of temperature. This technique is widely used in polymer or pharmaceutical industry, for property analysis of material/drugs.

$$
\Delta \Phi_{S R}=\Phi_{S}-\Phi_{R}
$$

where:

$\Delta \Phi_{S R}$ - the quantity of heat necessary to raise the temperature of the material by dT,

$\Phi_{S}$ - combustion heat of the sample,

$\Phi_{R}-$ combustion heat of the reference sample.

\section{MATERIALS AND METHODS}

Preliminary thermogravimetric testing of samples of waste was conducted on the Simultaneous Thermal Analyser STA 449 F3 Jupiter ${ }^{\circledR}$ of the Netzsch company. In the analyser mentioned above the samples ( $\mathrm{S}$ and $\mathrm{R}$ ) were placed symmetrically in identical measuring vessels $\left(\mathrm{Al}_{2} \mathrm{O}_{3}\right.$ crucibles) in the same furnace whose temperature was regulated according to an assumed temperature regime, regardless of the changes in the properties of the samples during the measurement. The temperature program assumed heating the sample from $30{ }^{\circ} \mathrm{C}$ to $500{ }^{\circ} \mathrm{C}$ with a heating rate of $10 \mathrm{~K} / \mathrm{min}$. Argon was used as protective gas with flow rate of $20 \mathrm{~mL} / \mathrm{min}$, and $\mathrm{N}_{2}$ as purge gas with flow rate of 50 $\mathrm{mL} / \mathrm{min}$. 
The thermal analyser measured the difference in temperatures between the samples:

$$
\Delta T_{S R}=T_{S}-T_{R}
$$

$\Delta T_{S R}$ - difference in temperature of the sample and the reference sample,

$T_{S}$ - temperature of the sample,

$T_{R}$ - temperature of the reference sample.

When the analyser furnace is heated and the system is thermally symmetric, an identical heat flux flows to both samples and their difference in temperature is then zero. If this state of dynamic equilibrium was disturbed by a change in either sample, or if there was thermal asymmetry of the system caused by a difference in the heat capacity of the samples, the DSC measurement showed differences in temperature, $\Delta T_{S R} \neq 0$, in proportion to the differences in the heat fluxes to the sample and to the reference sample, and then

$$
\Delta \Phi_{S R}=-k \Delta T_{S R}
$$

where:

$k$ - proportionality constant with the nature of the inverse of thermal resistance.

Used as raw materials in our experiments were:

- polyethylene terephthalate which was chosen from an plastic bottle;

- HDPE (High Density Polyethylene) - a plastic bag for food;

- LLDPE - (Linear Low Density Polyethylene) - shrink film;

- a granulated car radial tire.

\section{PRELIMINARY TESTING RESULTS}

The results of the measurement made with the use of the DSC technique were DSC curves - the dependence of the measured difference in the heat fluxes on time/temperature. The graphs in Fig. 1 and Fig. 2 present the course of derivatographic curves; the TG curves are marked in red, the DTA curves obtained by means of the DSC method - in blue.

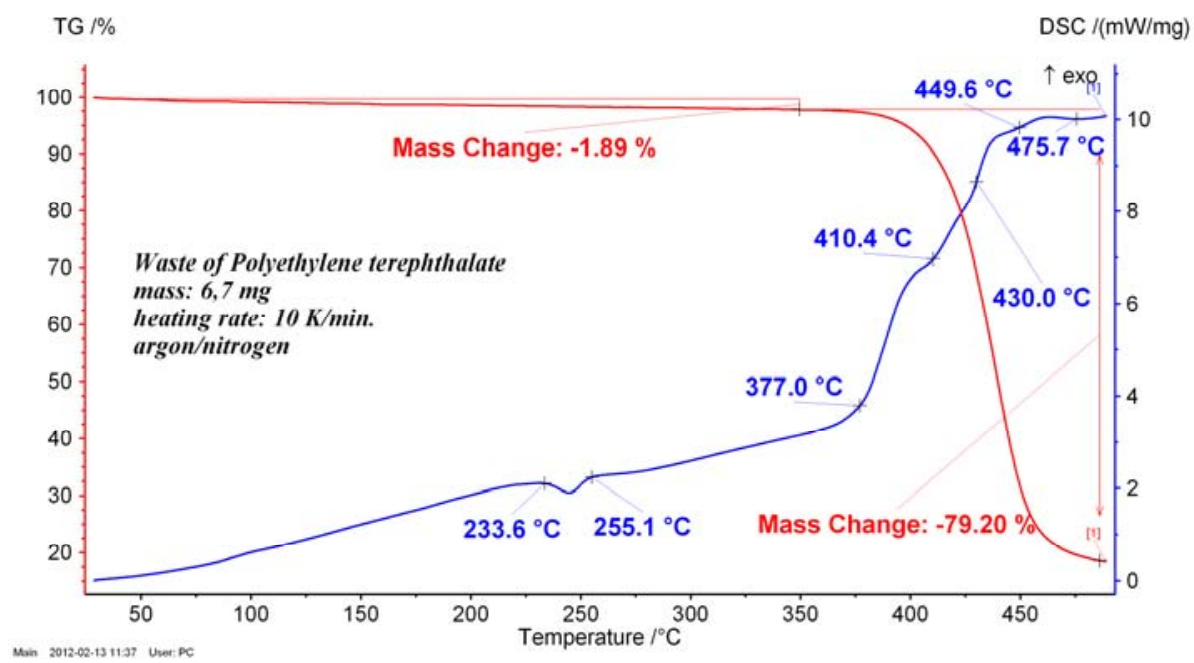

Figure 1. Thermogravimetric analysis of samples of PET conducted in a nitrogen atmosphere 
As a result of the process of thermal decomposition of PET samples (Fig. 1) were liquefaction of the material in the temperature range from $233.6^{\circ} \mathrm{C}$ to $255.1^{\circ} \mathrm{C}$. In fig. 1 we two stages of exothermic nature was observed. The first occurs in the temperature range from $377.0{ }^{\circ} \mathrm{C}$ to $410.4{ }^{\circ} \mathrm{C}$, and the other in the range of $430.0^{\circ} \mathrm{C}$ to $475.7^{\circ} \mathrm{C}$.

Initial thermal decomposition can be broadly seen as a two stage thermal degradation process consisting of primary decomposition and secondary reactions. During the primary steps of decomposition weak aliphatic bonds (non-aromatics) are broken. The fragments that do not condense at room temperature undergo further decomposition producing $\mathrm{CO}_{2}$, light aliphatic gases $\left(\mathrm{C}_{2}-\mathrm{C}_{5}\right)$ and $\mathrm{H}_{2} \mathrm{O}$. The secondary phase of pyrolytic thermal decomposition results in $\mathrm{CH}_{4}, \mathrm{CO}, \mathrm{H}_{2}$ and light volatile nitrogenous species $\left(\mathrm{NH}_{3}, \mathrm{HCN}\right.$ and $\left.\mathrm{H}_{i} \mathrm{NCO}\right)$. Volatile nitrogen is expected to be present in all the waste samples [15-17].

Thermal decomposition of rubber derived from waste tires (Fig. 2), characterized by an initial plasticity native material, and then the gradual gasification of time from about $270{ }^{\circ} \mathrm{C}$.

The temperature of $367.9{ }^{\circ} \mathrm{C}$ to $486.0{ }^{\circ} \mathrm{C}$ are endothermic nature of which may indicate the production of the gas phase, which, as far as raising the temperature may contain more and more methane, higher hydrocarbons at the expense of participation. TG and DSC curves indicate the possibility of formation of gaseous products such as carbon monoxide, carbon dioxide and hydrogen sulfide (sulfone).

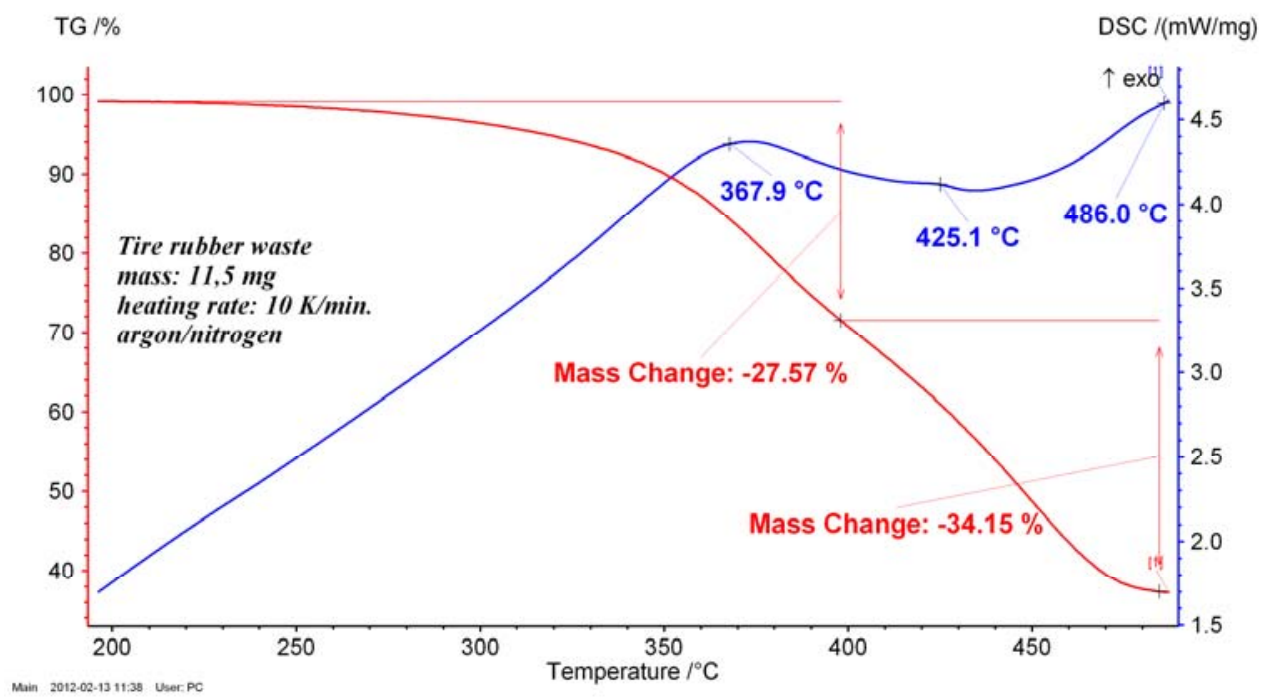

Figure 2. Thermogravimetric analysis of samples of a granulated car radial tire conducted in an atmosphere of nitrogen

Shown in Fig. 3 DSC curves of the nature of the changes for samples of different density polyethylene (High Density or Linear Low Density) in the process of thermal decomposition are similar [18]. The course of these curves confirms the radical nature of the distribution, consisting of a symmetrical break polymer chains, leading to the creation of two new radicals - for High Density Polyethylene this process generally begins from $431.6^{\circ} \mathrm{C}$, and for Linear Low Density Polyethylene of $427.9^{\circ} \mathrm{C}$. For the temperatures over $427.9^{\circ} \mathrm{C}$ (the LLDPE polymer waste sample) is noticeably small exothermic peak, which may result from intramolecular or intermolecular hydrogen transport. The exact interpretation of the DSC curves can be given only after the identification of gaseous decomposition products, as provided for in the next phases of research. 


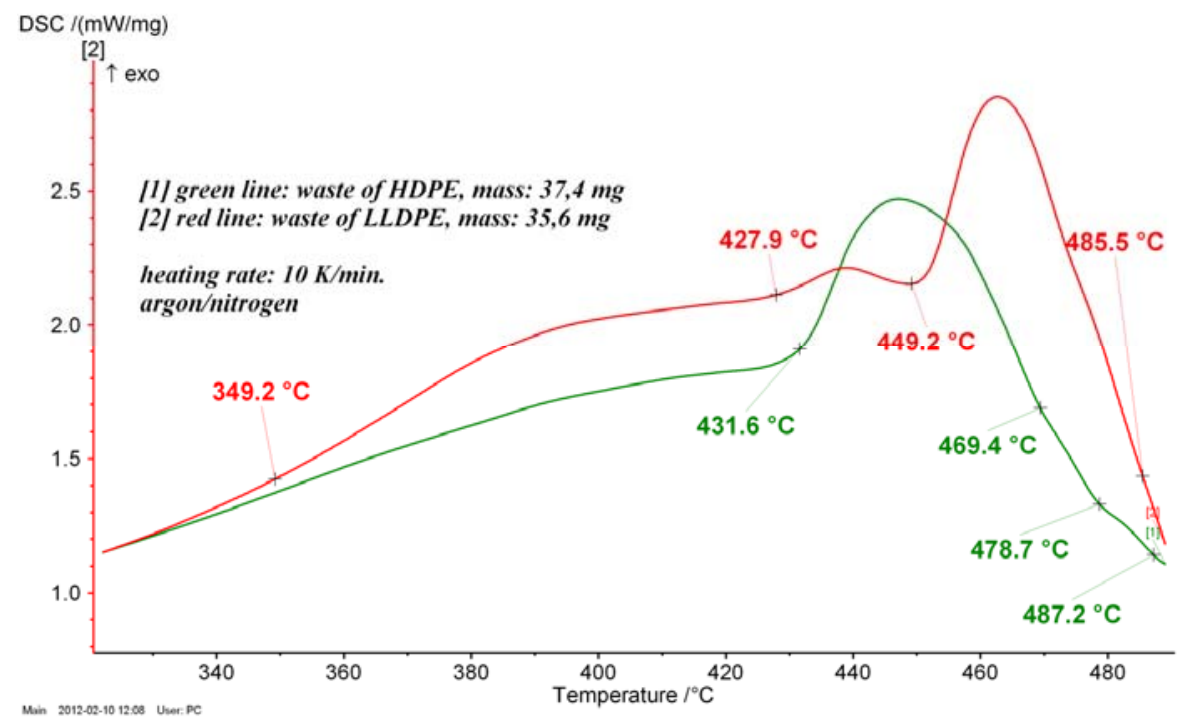

Figure 3. Thermogravimetric analysis of samples of varying density polyethylene conducted in a nitrogen atmosphere

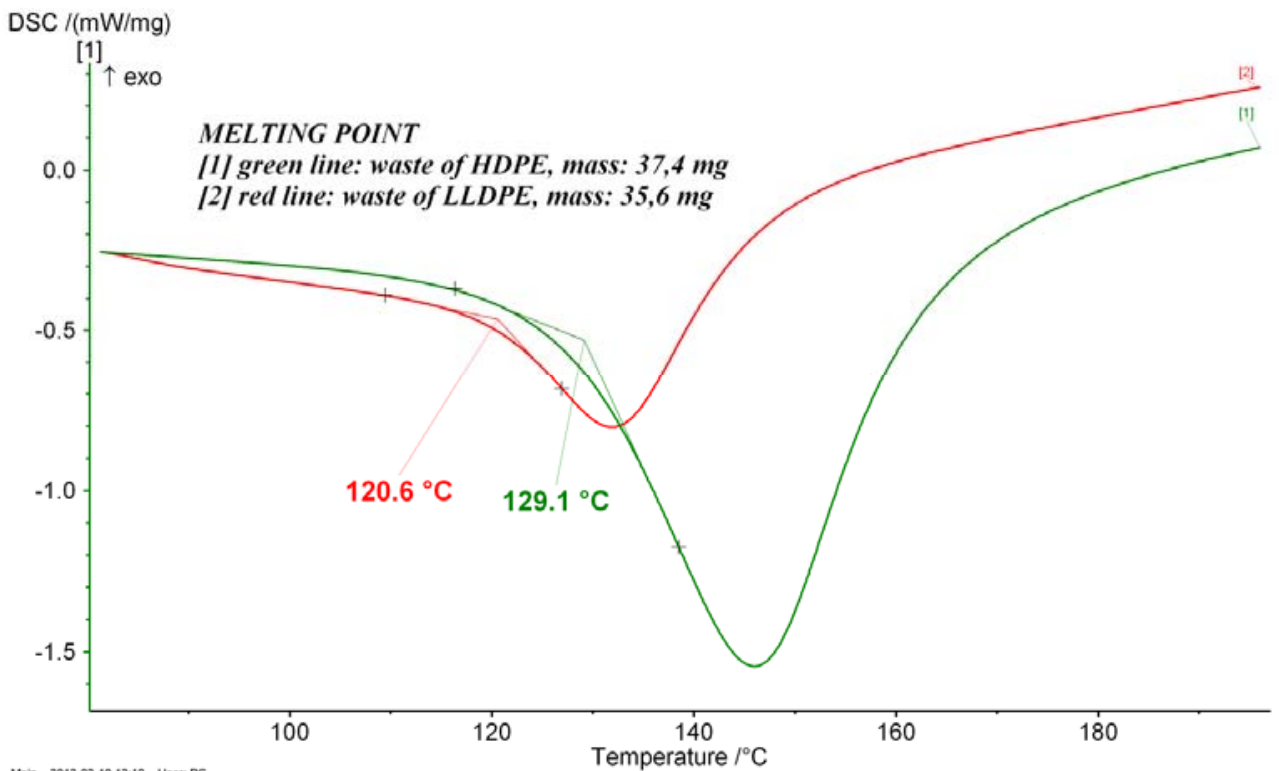

Figure 4. Melting points of samples of HDPE and LLDPE waste

For samples of polyethylene waste of different densities on the basis of DSC curves defined the beginning of the process of phase transitions (Fig. 4). The melting process for HDPE begins in $129.1{ }^{\circ} \mathrm{C}$ and for LLDPE in $120.6^{\circ} \mathrm{C}$. The difference results from the greater density of particles in the HDPE.

The values of enthalpy of the exothermic processes of decomposition of the waste of polyethylene terephthalene and of the waste of polyethylene are shown in Fig. 5. Enthalpy value for the degradation of PET $(\Delta H=633.2 \mathrm{~J} / \mathrm{g})$ is almost twice higher than the enthalpy for the decomposition process of sample PE which is $\Delta H=350.8 \mathrm{~J} / \mathrm{g}$.

Similarly, the stages of change for the sample of waste of polyethylene terephthalene begins at higher temperature. The values of enthalpy and the differences are due to the 
nature of bonds in the structure of the sample, and evidence of a radical process. Identification of the radicals planned in future studies will help to optimize the decomposition process and also to investigate the possible effect of catalysts on the process.

Fig. 6 shows the process of thermal decomposition of the sample of rubber derived from waste car tires. Meanwhile the distribution of the above-mentioned samples of rubber endothermic process was observed in the temperature range from $367.9{ }^{\circ} \mathrm{C}$ to $486.0^{\circ} \mathrm{C}$. The value of the enthalpy of the process is $\Delta H=-159.0 \mathrm{~J} / \mathrm{g}$. A negative value of enthalpy can be related to the energy needs associated with the formation of particulate methane assets. To verify the correctness of this assumptions is planned to determine the structure of gaseous products of decomposition of samples in real time.

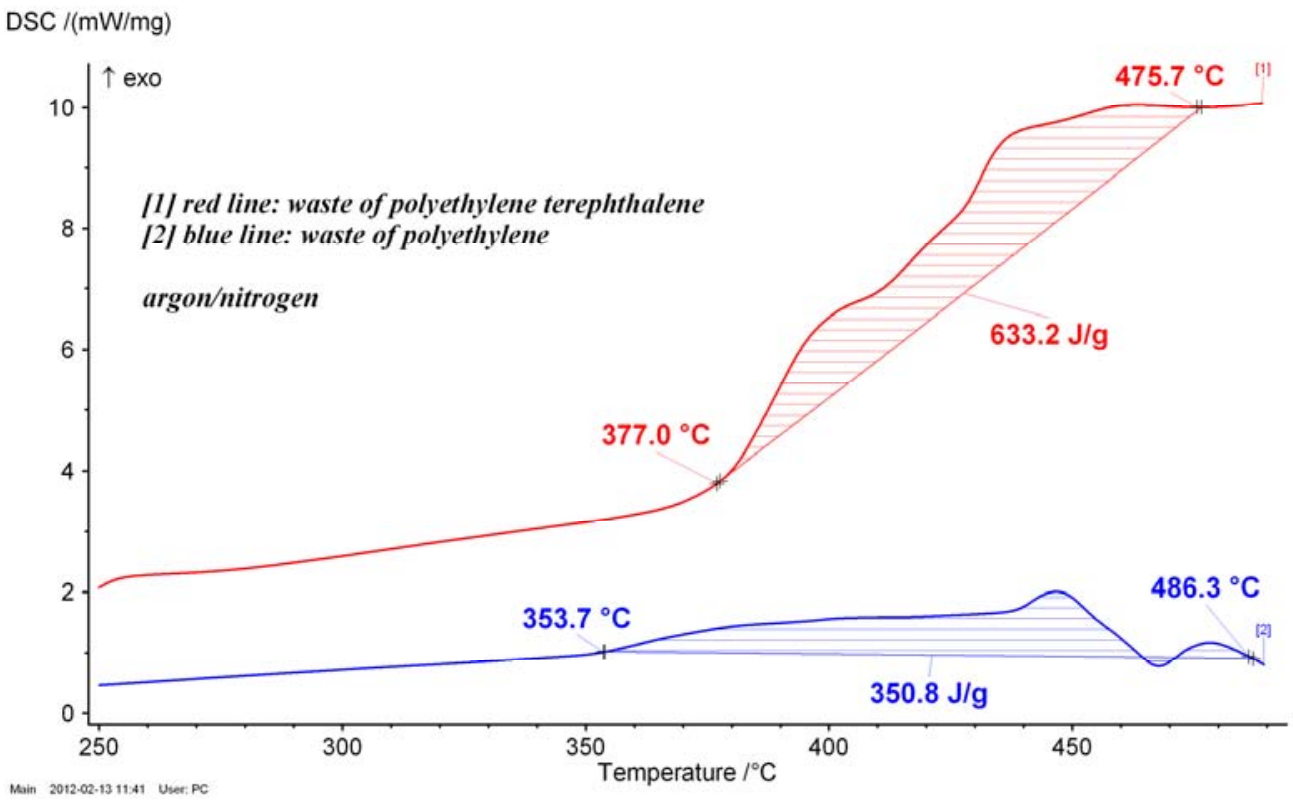

Figure 5. Enthalpy changes in the processes of thermal decomposition of samples of waste from PET and PE

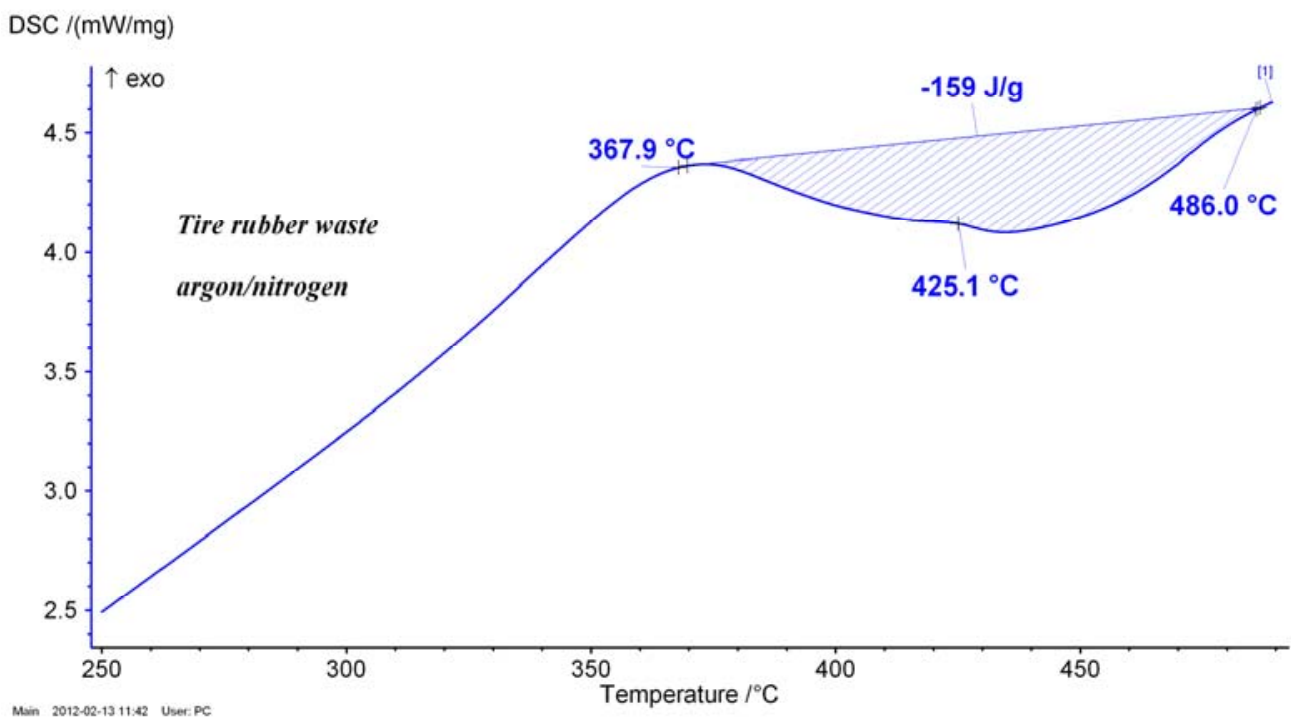


Figure 6. Enthalpy change in the process of thermal decomposition of tire rubber waste

\section{CONCLUSION}

The development of industry and consumer nature of life affects the drastic increase in the amount of waste. Therefore, it becomes necessary to implement technologies that the treatment of waste into energy and thus reduce the demand for conventional energy sources such as oil, natural gas or coal. The research programs and documents of the European Union introduced the concept of "alternative fuels", produced among other things from waste materials of industrial origin, and household usage, meeting the requirements of transport and heating equipment and electric power.

The thermogravimetric curves in the article shows that research derivatography basic research may be possible to describe the mechanisms of thermal decomposition of waste. These studies also allow the determination of the actual energy requirements in these processes and thus permits the development of optimal manufacturing processes to enable energy use of waste polymer and rubber, both in WtE and WtL processes.

The study showed the complexity of the decomposition of changes in both the kinetics of reactions occurring and the enthalpy change of the process. Thermal decomposition of selected plastic samples showed growth of enthalpy (slightly less for samples of PE) as a result of the size of the energy and type of chemical bonds. Thermal decomposition of granulated car radial tire, in the studied temperature range, is the endothermic nature of which could influence the energy balance of the process.

Studies on the $\mathrm{WtL} / \mathrm{WtE}$ analysis processes will be continued for a wider range of temperature, using equipment which delivers on-line identification of gaseous decomposition products.

\section{REFERENCES}

1. Miskolczi N., Bartha L., Deak G., Jover B., Thermal degradation of municipal plastic waste for production of fuel-like hydrocarbons, Polymer Degradation and Stability, No 86, pp. 357-366, 2004. (http://dx. doi.org/10.1016/j. polymdegradstab.2004.04.025)

2. Aguado J., Serrano DP. In: Clark JH, editor., Feedstock recycling of plastic wastes, Cambridge: RSC, 1999.

3. Sartorius I., Development of Plastics Manufacturing Industry in Europe, ICS-UNIDO Conference, Italy, 2002.

4. Wong ACY, Lam F., Study of selected thermal characteristics of polypropylene/polyethylene binary blends using DSC and TGA, Polym Test, No 21, pp. 691-6, 2002. (http://dx.doi.org/10.1016/S0142-9418(01)00144-1)

5. Joseph PV, Marcelo S., Rabello LH, Matusso S., Environmental effects on the degradation behaviour of sisal fibre reinforced polypropylene composites, Compos Sci Technol, No 62, pp. 1357-72, 2002. (http://dx.doi.org/10.1016/S0266-3538(02)00080-5)

6. Ballice L., Reimert R., Classification of volatile products from the temperature programmed pyrolysis of polypropylene (PP), atac-tic-polypropylene (APP) and thermogravimetrically derived kinetics of pyrolysis, Chem Eng Process, No 41, pp. 289-96, 2002. (http://dx.doi.org/10.1016/S0255-2701(01)00144-1)

7. Rostek E., Biernat K., Thermogravimetric Biomass-To-Liquid processes, Journal of KONES Powertrain and Transport, Vol. 18, No 2, pp. 377-383, 2011.

8. Basu P., Kaushal P.: Modeling of Pyrolysis and Gasification of Biomass in Fluidized Beds, Chemical Product and Process Modeling, Vol. 4, Issue 1, article 21, 2009. 
9. Koufopanos C.A., Maschio G., Lucchesi A.: Kinetic modeling of the pyrolysis of biomass components, Canadian Journal of Chemical Engineering, Nr 67, pp.75-84, 1989. (http://dx.doi.org/10.1002/cjce.5450670111)

10. ICTAC Nomenclature of Thermal Analysis, ICTAC News, Nr 37/2, pp. 62-70, 2004.

11. Williams P.T.,Besler S., Pyrolysis-thermogravimetric analysis of tyres and tyre components, Fuel, No 14, pp.1277-1283, 1995.

(http://dx.doi.org/10.1016/0016-2361(95)00083-H)

12. Singh S., Wu C., Williams P.T., Pyrolysis of waste materials using TGA-MS and TGA-FTIR as complementary characterisation techniques, Journal of Analytical and Applied Pyrolysis, Article in Press, 2011.

13. Duan H.B., Li J.H., Thermal degradation behaviour of waste video cards using thermogravimetric analysis and pyrolysis gas chromatography/mass spectrometry techniques, J. Air Waste Manage. Assoc., No 60, pp. 540-547, 2010. (http://dx.doi.org/10.3155/1047-3289.60.5.540)

14. Na D., Yu-Feng Z., Yan W., Thermogravimetric analysis and kinetic study of representative medical waste composition, Waste Manage., No 28, pp. 1572-1580, 2008.

15. Solomon P.R., Serio M.A., Suuberg E.M., Coal pyrolysis: experiments kinetic rates and mechanisms, Prog. Energy Combust. Sci., No 18, pp. 133-220, 1992.

16. Glarborg P., Jenses A.D., Johansson J.E., Prog. Energy Combust. Sci., 29, pp. 89-113, 2003. (http://dx.doi. org/10.1016/S0360-1285(02)00031-X)

17. Zhao M., Florin N.H., Harris A.T., Mesoporous supportes cobalt catalysts for enhanced hydrogen production during cellulose decomposition, Appl. Catal. B: Environ., No 97, pp. 142-150, 2010. (http://dx.doi.org/10.1016/j.apcatb. 2010.03.034)

18. Kumar S., Panda A.K., Singh R.K., A review on tertiary recycling of high-density polyethylene to fuel, Recources, Conservation and Recycling, No 55, pp. 893-910, 2011. 